\title{
O BOM CIDADÃO DOCENTE UNIVERSITÁRIO NA SENDA DA QUALIDADE NO EN SINO SUPERIOR
}

Arménio Rego*

RESU M 0: Este artigo representa uma extensão de trabal ho prévio realizado no domínio dos comportamentos de cidadania dos professores universitários (Cidoce). 0 seu objectivo é o de mostrar como quatro categorias de Cidoce (comportamento participativo, orientação prática, conscienciosidade e cortesia) influenciam a motivação profissional e autoconfiança dos estudantes (actuais ou antigos), assim a cotação global de desempenho que estes Ihes atribuem. Retomam-se dados de investigação anteriormente realizada com amostras de estudantes e professores (Rego \& Sousa, 2000), procedendo-se à inclusão de uma amostra de diplomados com curso superior. $\mathrm{Na}$ globalidade, foram inquiridos 249 estudantes, 123 professores e 209 diplomados. Os estudantes debruçaram-se sobre actuais docentes, e os professores e diplomados foram convidados a descrever os comportamentos dos seus antigos mestres. O s resultados revelam o seguinte: a) os três tipos de participantes nos estudos declaram que as quatro categorias de cidadania influenciam significativamente a sua motivação profissional e autoconfiança; b) todoseles ponderam fortemente esses quatro comportamentos quando são chamados a notar o desempenho global dos seus professores. A consistência desta evidência sugere que podemos estar em presença de comportamentos docentes com forte potencial de melhoria da qualidade do ensino superior, nomeadamente no que concerne à qualidade do processo ensino-aprendizagem.

Palavras-chave: Q ualidade no ensino superior; Comportamentos de cidadania dos professores universitários; Autoconfiança; M otivação profissional.

* Secção Autónoma de G estão e Engenharia Industrial da Universidade de Aveiro (Portugal). Email: arego@egi.ua.pt 
Introdução

\section{Q ualidade versus processo ensino-aprendizagem}

A qualidade no ensino superior tem ocupado, nos últimos anos, um lugar de destaque, seja no discurso dos agentes educativos, nas preocupações dos decisores políticos, ou na literatura especializada (v.g., H orine, H ailley \& Rubach, 1993; Schargel, 1994; Ellington \& Ross, 1994; Ace, 1994; Feigenbaum, 1994; H elms \& K ey, 1994; Sirvanci, 1996; Rowley, 1996; H ansen \& Jackson, 1996; Bailey \& Bennett, 1996; M assy, 1997; H orsburgh, 1999; M ontano \& Utter, 1999; Zabalza, 1999). Esta significativa expressão do tópico representa, em grande medida, a expansão para o domínio educativo de uma filosofia de gestão que, desde há muito, se vem tentando implementar nas empresas industriais e de serviços (v.g., H ackman \& Wageman, 1995; Shemwell, Yavas, \& Bilgin, 1998; Zbaracki, 1998).

Para se al cançarem efectivas melhorias qualitárias, importa, todavia, descortinar as áreas de pesquisa e intervenção mais pertinentes. Se se pretende evitar que a eficácia da acção fique seriamente comprometida, é crucial extraír do "terreno" os ensinamentos mais frutuosos. Sucede que, neste domínio, o processo ensino-aprendizagem tem sido referido por diversos estudiosos da qualidade (v.g., Schargel, 1994; Ellington \& Ross, 1994; Bailey \& Bennett, 1996; H ansen \& Jackson, 1996; Rowley, 1996; Yorke, 1997; H orsburgh, 1999) como uma das áreas de intervenção com maior potencial. Helms \& Key (1994) enunciaram eloqüentemente essa tese ao afirmarem que "não há lugar algum onde os resultados positivos da gestão da qualidade total sejam mais necessários do que... na sala de aula" (p. 97). Este artigo insere-se nesse domínio de preocupações e procura dar resposta a um desafio expressivamente manifestado por $\mathrm{H}$ ansen \& Jackson (1996): "Apesar do extenso discurso sobre a qualidade, a actividade nuclear das universidades - a docência - permanece em grande medida intacta" (pp. 211-212).

É possível que este déficit tenha a sua génese na dificuldade que 0 campo encerra (v.g. H elms \& K ey, 1994; Rowley, 1996). M as tal não deve (não pode!) ser impeditivo de que novas pesquisas e contributos sejam procurados e lançados para discussão. Acresce que as ausências e carências contêm, quase sempre, duas facetas: um obstáculo e... uma oportunidade. Constituem, até, um convite à criatividade, investigação, reflexão e descoberta de linhas de orientação potencialmente contributivas de melhores desempenhos individuais e organizacionais. Um olhar atento 
permite, aliás, verificar que alguns caminhos proveitosos já começaram a ser rasgados. Com efeito, é possível identificar na literatura um elenco significativo de comportamentos docentes com potenciais efeitos positivos sobre os estudantes e, globalmente, o processo de ensino-aprendizagem. A título ilustrativo podem citar-se (v.g., Ellington \& Ross, 1994; H elms \& Key, 1994; Rowley, 1996; Stringer \& Irving, 1998; M arsh et al., 1998; H orsburgh, 1999):

a) feedback da aprendizagem pontual e justo;

b) preparação dos materiais;

c) clareza das explicações;

d) pontualidade;

e) entusiasmo;

f) dinamismo;

g) encorajamento da participação;

h) actuação amistosa, interesse pelos estudantes e disponibilidade para os atender;

i) espírito de diálogo e práticas reflexivas partilhadas;

j) credibilidade e fiabilidade nas avaliações;

k) promoção da autonomia e da aprendizagem activa;

l) justiça, cortesia e conscienciosidade no exercício do papel docente.

\section{Comportamentos de cidadania docente universitária}

Alguns dos comportamentos mais vincados nessas pesquisas apresentam semelhanças com os comportamentos de cidadania docente universitária (Cidoce). Estes podem ser definidos como os comportamentos (tendencialmente) discricionários, não directa ou explicitamente reconhecidos pelo sistema de recompensa formal, e que contribuem para o funcionamento eficaz da organização universitária, designadamente no que concerne ao desempenho académico dos estudantes.

Esta definição tem a sua génese no conceito de comportamentos de cidadania organizacional (Smith, O rgan \& N ear, 1983; Van Dyne, Cummings \& Parks, 1995; O rgan \& Ryan, 1995; Organ, 1988, 1997; Podsakoff et al., 1997; N etemeyer et al., 1997; M ack enzie et al., 1998; Organ \& Paine, 1999), tendo sido adaptada e desenvolvida por Rego \& 
Sousa (Rego, 1999; Rego \& Sousa, 1999a). Depois de obterem itens na literatura (M arsh et al., 1998; Stringer \& Irwing, 1998; Rego \& Sousa, 1999b) e de analisarem o material semântico obtido em entrevistas semiestruturadas junto de 49 estudantes e 7 professores universitários (a quem foi solicitado que referissem actos característicos de antigos professores que considerassem excelentes), os dois investigadores operacionalizaram o constructo, tendo descortinado quatro dimensões:

a) 0 comportamento participativo representa a promoção do diálogo e o fomento da participação dos estudantes no processo pedagógico.

b) A orientação prática reflete a preocupação pedagógica do docente em ilustrar a explanação das matérias com exemplos práticos e interessantes para a vida dos estudantes.

c) A conscienciosidade pedagógica respeita aos comportamentos reveladores de uma postura preocupada com o exercício rigoroso da função docente (v.g., preparar bem as aulas, ser exigente, dar as aulas com rigor e seriedade).

d) A (des)cortesia representa um tratamento (des)respeitador dos estudantes.

N as suas investigações, Rego \& Sousa enfatizaram as ações pedagógicas mais presumivelmente ligadas ao desempenho dos estudantes, procurando suprir a ausência de estudos nessa matéria. Enveredaram por uma tal veia comportamental por três razões:

a) Em primeiro lugar, notaram que os instrumentos e constructos de cidadania disponíveis secundarizavam os actos direccionados para os estudantes. Com efeito, o instrumento usado por Koh, Steers \& Terborg (1995) resultou de uma adaptação do instrumento desenvolvido por Smith, O rgan \& N ear (1983), sendo este destinado a medir os comportamentos de cidadania organizacional. Por seu turno, o questionário usado por Skarlicki \& Latham (1995) enfatizou os actos direccionados para a organização escolar e os colegas docentes.

b) Em segundo lugar, pareceu-Ihes lógico que o estudo empírico das relações entre os Cidoce e os impactos sobre os estudantes (com especial destaque para os desempenhos académicos) seria 
mais profícuo se fossem pesquisados comportamentos de relacionamento entre docentes e estudantes - mais do que actos direccionados para os colegas docentes (v.g., ajuda na revisão de um artigo) ou para a organização (v.g., fornecer sugestões de melhoria do funcionamento administrativo da instituição).

c) Em terceiro lugar, procuraram responder ao desafio lançado por $\mathrm{H}$ ansem \& Jackson (1996): "A menos que se actue sobre 0 processo ensino-aprendizagem, as mudanças na gestão da qualidade suscitarão, apenas, benefícios diminutos" (p. 211-212. Grifo nosso).

0 presente artigo visa expor os resultados de diversos estudos cujo objectivo éo de relacionar os comportamentos de cidadania dos professores universitários com três variáveis: a) o desempenho global dos professores, tal como atribuído pelos seus alunos (actuais ou antigos); b) a motivação profissional e a auto-confiança dos seus estudantes. Sucinta e simplesmente, será exposta diversa evidência empírica susceptível de contribuir para responder a duas questões básicas. Primeira: o que significa ser um "excelente" professor universitário? Segunda: haverá diferenças entre as concepções de estudantes, professores e diplomados com curso superior?

\section{M etodologia}

Foram inquiridos 249 estudantes universitários, 123 professores e 209 diplomados com curso superior. Os estudantes provinham de 27 cursos superiores (das áreas de letras/humanidades, engenharias, ciências, gestão/economia) e freqüentando entre 0 1ㅇ e 0 50 ano. Os professores exerciam actividade na U niversidade de Aveiro, distribuindo-se por diversos departamentos (gestão, engenharia, química, física, educação, biologia, geologia, comunicação e arte, matemática) dessa instituição. O s diplomados eram detentores de diplomas de diversa natureza, exerciam actividades profissionais diversas e haviam terminado os seus cursos em momentos bastante distintos. A sua caracterização encontra-se em anexo.

O s participantes foram abordados do seguinte modo: a) os estudantes foram convidados a reflectir sobre um actual professor, à sua escolha; b) aos professores e diplomados foi solicitado que reflectissem sobre um antigo docente, também à sua escolha. A todos foi proposto que escolhessem e pensassem num docente, cujo comportamento pudessem descrever com algum rigor, independentemente de gostarem ou 
não dele, de o considerarem ou não competente, e qualquer que fosse 0 sexo, idade ou área de actividade. 0 inquérito que lhes foi proposto continha três partes principais:

a) N a primeira, a pessoa era convidada a responder ao questionário de medida dos $\mathrm{C}$ idoce, assinalando em que medida as afirmações enunciadas se aplicavam ao docente em que havia pensado, através de uma escala tipo Likert de 7 pontos (1: "não se aplica nada"; ... ; 7: "aplica-se completamente"). 0 questionário tem duas versões. $\mathrm{N}$ a sua forma extensa (aplicada aos estudantes), comporta 32 itens. $\mathrm{N}$ a sua forma reduzida (respondida por professores e diplomados), integra 14 descritores (Tabela 1). N 0 presente artigo, para efeitos comparativos, apenas se apresentam os dados relativos à forma sucinta.

b) $\mathrm{N}$ a segunda parte, era solicitado ao inquirido que referisse os impactos que esse professor havia exercido sobre si, através de 10 escalas de diferencial semântico (também com 7 pontos). Estes descritores haviam sido recolhidos por Rego \& Sousa (Rego, 1999; Rego \& Sousa, 1999a) em duas fontes. Primeira: entrevistas semi-estruturadas a 13 estudantes, os quais foram convidados a pensar em excelentes (antigos) professores, e a reportar os efeitos que eles haviam exercido sobre a sua vida. Segunda: análise do material semântico obtido na fase exploratória de recolha de itens para 0 instrumento de medida dos Cidoce. Com efeito, os 49 estudantes e 7 professores participantes nesse estudo exploratório não se limitaram a citar comportamentos, antes extravasaram para os efeitos sentidos e para as razões pelas quais consideravam exemplares os professores escol hidos. c) $\mathrm{Na}$ terceira, solicitava-se ao indivíduo que atribuísse uma cotação global de desempenho ao professor em mente, numa escala de 1 ("péssimo professor") a 20 ("excelente professor"). Esta escala é similar à que é utilizada pelos docentes para avaliarem o desempenho dos seus alunos.

O s dados de cidadania e impactos foram sujeitos a uma análise factorial confirmatória (Joreskog \& Sorbom, 1993; Byrne, 1998). Foi testado o modelo de seis dimensões emergente da investigação de Rego (1999): quatro para a cidadania e duas para os impactos (motivação profissional e auto-confiança) - o resultado encontra-se na Tabela 1. G lobalmente, os índices de ajustamento do modelo são satisfatórios e as consistências internas satiffazem o valor mínimo de 0.70 sugerido por N unnally (1978). 
Tabela 1

Análisefactorial confirmatória (solução completamenteestandardizada)

\begin{tabular}{|c|c|}
\hline & $\begin{array}{c}\text { Diplomados + } \\
\text { professores + } \\
\text { estudantes } \\
(n=581)\end{array}$ \\
\hline Comportamento participativo & $(0.82)$ \\
\hline Fomenta a participação dos alunos na aula. & 0.81 \\
\hline Dialoga abertamente com os alunos. & 0.82 \\
\hline Quando pede a opinião dos alunos... toma as ideias deles em consideração. & 0.79 \\
\hline Orientação prática & $(\mathbf{0 . 8 8})$ \\
\hline Os exemplos que dá na aula são interessantes para a vida dos alunos. & 0.85 \\
\hline Nas aulas, alerta para o sentido prático das coisas. & 0.88 \\
\hline Ilustra a exposição da matéria com exemplos práticos. & 0.80 \\
\hline Conscienciosidade & $(0.91)$ \\
\hline Expõe a matéria de modo organizado. & 0.89 \\
\hline Nas aulas, não segue um fio de pensamento (i.e., "mistura tudo") (I). & -0.79 \\
\hline Prepara bem as aulas. & 0.85 \\
\hline É metódico na exposição da matéria. & 0.82 \\
\hline (Des)Cortesia & $(\mathbf{0 . 8 5})$ \\
\hline Culpa os alunos pelos maus resultados (I). & 0.67 \\
\hline Marginaliza os alunos de que não gosta (I). & 0.84 \\
\hline Trata com indiferença os alunos menos bons (I). & 0.78 \\
\hline $\begin{array}{l}\text { Quando os alunos vão ao gabinete para esclarecer dúvidas... faz troça dos } \\
\text { erros cometidos (I). }\end{array}$ & 0.76 \\
\hline Motivação profissional & $(\mathbf{0 . 8 8})$ \\
\hline Sentimento de preparação para enfrentar as dificuldades ao longo da vida. & 0.79 \\
\hline Interesse pelo curso. & 0.76 \\
\hline Sentimento de preparação para ingressar no mundo do trabalho. & 0.78 \\
\hline Motivação para estudar. & 0.75 \\
\hline Influência marcante na vida. & 0.75 \\
\hline Auto-confiança & $(0.70)$ \\
\hline Força para enfrentar as dificuldades da vida. & 0.74 \\
\hline Relação com os colegas. & 0.44 \\
\hline Autoconfiança. & 0.78 \\
\hline
\end{tabular}




\begin{tabular}{lc} 
Índices de ajustamento & \\
\hline Qui-quadrado (p) & $540.78(0.000)$ \\
Qui-quadrado/Graus de liberdade & 0.057 \\
Root mean square root of approximation & 0.92 \\
Goodness of fit index & 0.90 \\
Adjusted goodness of fit index & 0.71 \\
Parsimony goodness of fit index & 0.93 \\
Normed fit index & 0.94 \\
Non-normed fit index & 0.78 \\
Parsimony normed fit index & 0.95 \\
Comparative fit index & 0.95 \\
Incremental fit index & 0.91 \\
Relative fit index & 244.303 \\
\hline
\end{tabular}

Entre parêntesis: alphas de Cronbach

(I) AS PONTUAÇÕES NESTES ITENS FORAM INVERTIDAS.

\section{Resultados}

A Tabela 2 expõe as médias, desvios-padrão e correlações entre as variáveis. Em geral, as variáveis de cidadania relacionam-se significativamente entre si, com as duas variáveis de impacto (especialmente a motivação profissional) e a cotação global de desempenho. Estes valores correlativos são similares para os três tipos de inquiridos (estudantes, professores e diplomados).

A Tabela 3 expõe os resultados para as análises de regressão. Procura evidenciar o poder explicativo das dimensões de cidadania para a cotação de desempenho, a motivação profissional e a auto-confiança. A sua leitura permite extrair algumas tendências, designadamente:

a) Todas as variáveis de cidadania explicam de modo bastante expressivo a cotação de desempenho e a motivação profissional. O u seja, tanto estudantes como professores e graduados ponderam fortemente esses quatro tipos de comportamento quando avaliam o desempenho dos seus mestres (actuais ou antigos), e quando reflectem sobre a influência por eles exercida na sua própria motivação profissional. O s efeitos exercidos pelos Cidoce sobre a autoconfiança são menos notórios.

b) 0 poder explicativo das quatro dimensões de cidadania para as variáveis de impacto e de desempenho global é superior entre os já diplomados do que no seio dos estudantes e professores inquiridos em estudos anteriores. A diferença é mais notória para a autoconfiança. 
Tabela 2

Médias, desviospadrão ecorrelações

\begin{tabular}{|c|c|c|c|c|c|c|c|c|c|}
\hline & Média & $D P$ & 1 & 2 & 3 & 4 & 5 & 6 & 7 \\
\hline 1. Comportamento participativo & 4.3 & 1.5 & - & & & & & & \\
\hline 2. Orientação prática & 4.4 & 1.5 & 0.70 & - & & & & & \\
\hline 3. Conscienciosidade & 5.2 & 1.5 & 0.39 & 0.46 & - & & & & \\
\hline 4. Cortesia & 5.4 & 1.5 & 0.52 & 0.42 & 0.43 & - & & & \\
\hline 5. Cidoce global (média das 4 dimensões)* & 4.8 & 1.2 & 0.84 & 0.82 & 0.73 & 0.75 & - & & \\
\hline 6. Motivação profissional & 4.7 & 1.4 & 0.67 & 0.74 & 0.59 & 0.54 & 0.81 & - & \\
\hline 7. Autoconfiança & 4.6 & 0.9 & 0.42 & 0.46 & 0.33 & 0.36 & 0.50 & 0.66 & - \\
\hline 8. Cotação de desempenho docente & 13.5 & 5.0 & 0.71 & 0.69 & 0.65 & 0.58 & 0.84 & 0.84 & 0.49 \\
\hline
\end{tabular}


Tabela 3

Regressões-poder explicativo dosCidoce

paraacotação global dedesempenho eas variáveis deimpacto

\begin{tabular}{|c|c|c|c|c|c|c|c|c|c|}
\hline & \multicolumn{3}{|c|}{$\begin{array}{l}\text { Estudantes } \\
\qquad(\mathrm{n}=249)\end{array}$} & \multicolumn{3}{|c|}{$\begin{array}{l}\text { Professores } \\
\qquad(\mathrm{n}=123)\end{array}$} & \multicolumn{3}{|c|}{$\begin{array}{c}\text { Diplomados } \\
(\mathrm{n}=209)\end{array}$} \\
\hline & $\begin{array}{r}\text { Cotacão de } \\
\text { desempenho }\end{array}$ & $\begin{array}{c}\text { Motivação } \\
\text { profissional }\end{array}$ & $\begin{array}{c}\text { Auto- } \\
\text { confiança }\end{array}$ & $\begin{array}{r}\begin{array}{r}\text { Cotação de } \\
\text { desempenho }\end{array} \\
\end{array}$ & $\begin{array}{c}\text { Motivação } \\
\text { profissional }\end{array}$ & $\begin{array}{c}\text { Auto- } \\
\text { confiança }\end{array}$ & $\begin{array}{c}\text { Cotacãa de } \\
\text { desempenho }\end{array}$ & $\begin{array}{c}\text { Motivação } \\
\text { profissional }\end{array}$ & $\begin{array}{c}\text { Auto- } \\
\text { confiança }\end{array}$ \\
\hline Comp. participativo & $0.47^{* * *}$ & $0.32 * * *$ & $0.24 *$ & $0.19^{* * *}$ & $0.17^{*}$ & $0.19^{*}$ & $0.25^{* * *}$ & $0.16^{* *}$ & 0.05 \\
\hline Orientação prática & $0.15^{* *}$ & $0.37 * * *$ & 0.13 & $0.25^{* * * *}$ & $0.44^{* * *}$ & $0.36^{* * *}$ & $0.22 * * *$ & $0.36^{* * *}$ & $0.20 * *$ \\
\hline Conscienciosidade & $0.28^{* * *}$ & $0.19^{* * *}$ & 0.07 & $0.41^{* * * *}$ & $0.26^{* * *}$ & -0.03 & $0.36^{* * *}$ & $0.31^{* * *}$ & $0.19 * *$ \\
\hline Cortesia & $0.15^{* * *}$ & $0.13^{* *}$ & 0.04 & $0.20^{* * * *}$ & $0.13^{*}$ & 0.07 & $0.25^{* * *}$ & $0.17^{* * *}$ & $0.32 * * *$ \\
\hline $\mathrm{F}$ & $124.86^{* * * *}$ & $107.96^{* * *}$ & $11.38^{* * *}$ & $11.38 * * *$ & 0.57 & $2.87^{* * * *}$ & $204.97 * * *$ & $125.13^{* * *}$ & 37.66 *** \\
\hline $\mathrm{R}^{2}$ ajustado & $67 \%$ & $64 \%$ & $15 \%$ & $71 \%$ & $59 \%$ & $28 \%$ & 0.79 & 0.70 & 0.40 \\
\hline
\end{tabular}


c) 0 s diplomados ponderam a cortesia mais fortemente do que os indivíduos das outras duas amostras. Ela representa, mesmo, a variável com influência mais significativa sobre a autoconfiança.

d) Q uando se trata de avaliar o desempenho global dos docentes, os diplomados e os professores ponderam a conscienciosidade e a orientação prática em maior grau do que os estudantes. Estes, por seu turno, valorizam mais o comportamento participativo.

e) A orientação prática representa a categoria de cidadania mais fortemente relacionada com a motivação profissional declarada, seja para os estudantes, os professores ou os diplomados.

f) Enquanto os estudantes declaram que os seus níveis de autoconfiança crescem com o comportamento participativo dos seus mestres, os diplomados ponderam as outras três categorias. O s professores, por seu turno, valorizam a orientação prática e, menos claramente, a postura participativa.

Para testarmos a eventual existência de efeitos moderadores provocados pelo tipo de curso realizado, a actividade profissional dos diplomados e o tempo decorrido desde o terminus do curso, executámos regressões para: a) quatro tipos de curso (via-ensino e humanidades, ciências, engenharias, economia/gestão); b) três tipos de ocupação (técnicos superiores, professores do ensino secundário, gestores/directores); c) três períodos temporais pós-curso (menos de 3 anos, entre 3 e 8 anos, e mais de 8 anos). $\mathrm{N}$ ão foram detectadas particularidades dignas de registo, exceptuando uma pequena tendência: os diplomados com cursos de engenharia são mais sensíveis à orientação prática.

A tabela 4 expõe a caracterização de seis agrupamentos de docentes (os escolhidos pelos diplomados inquiridos), oriundos de uma análise de clusters (Bryman \& C ramer, 1990; Reis, 1991; Pestana \& G ageiro, 1998). A análise foi baseada nas quatro dimensões de cidadania. Após 0 agrupamento procedeu-se a uma análise de variância (Teste Scheffé) tendo em vista conhecer as diferenças inter-grupos nas variáveis de cidadania, de impacto e de desempenho global. O s agrupamentos podem ser assim caracterizados:

a) O s docentes do grupo 1 foram denominados "Fracos" por apresentarem baixas notações em todas as dimensões de cidadania. Todos os tipos de inquiridos Ihes atribuem cotação de desempenho bastante "negativa". O s efeitos exercidos sobre a mo- 
Tabela 4

D esempenho global eimpactos dos docentes com diferentes configurações de cidadania (Valores médios para cada grupo)

\begin{tabular}{lccccccc}
\hline & $\begin{array}{c}\text { Grupo 1 } \\
\text { Fracos }\end{array}$ & $\begin{array}{c}\text { Grupo 2 } \\
\text { ('Apenas') } \\
\text { corteses }\end{array}$ & $\begin{array}{c}\text { Grupo 3 } \\
\text { Conscienc } \\
\text { iosos }\end{array}$ & $\begin{array}{c}\text { Grupo 4 } \\
\text { Regulares }\end{array}$ & $\begin{array}{c}\text { Grupo 5 } \\
\text { Profissionais } \\
\text { diligentes }\end{array}$ & $\begin{array}{c}\text { Grupo 6 } \\
\text { Exemplares }\end{array}$ & $\begin{array}{c}N^{\circ} \text { de pares } \\
\text { de grupos } \\
\text { diferentes* }\end{array}$ \\
\hline Comportamento participativo & 2.6 & 3.1 & 2.6 & 4.6 & 4.9 & 5.5 & 11 \\
Orientação prática & 2.4 & 3.5 & 2.7 & 4.8 & 4.4 & 5.9 & 14 \\
Conscienciosidade & 2.8 & 3.3 & 5.6 & 4.0 & 5.8 & 6.2 & 13 \\
Cortesia & 2.9 & 5.5 & 4.9 & 4.5 & 6.3 & 6.0 & 13 \\
Cidoce global (média das & 2.7 & 3.9 & 3.9 & 4.5 & 5.3 & 5.9 & 13 \\
pontuações nos 4 Cidoce) & & & & & & & \\
\hline
\end{tabular}

Cotação de desempenho

docente

\begin{tabular}{cccccccc} 
Atribuída pelos estudantes & 5.9 & 9.3 & 9.3 & 13.6 & 15.0 & 16.5 & 11 \\
Atribuída pelos professores & 8.8 & 9.1 & 13.4 & 14.6 & 17.5 & 17.7 & 11 \\
Atribuída pelos graduados & 5.1 & 7.7 & 9.8 & 12.1 & $\mathbf{1 6 . 6}$ & $\mathbf{1 7 . 6}$ & 11 \\
\hline
\end{tabular}

Motivação profissional

$\begin{array}{cccccccc}\text { Estudantes } & 3.0 & 3.6 & 3.6 & 4.6 & 4.8 & 5.8 & 11 \\ \text { Professores } & 3.2 & 3.6 & 4.7 & 4.9 & 5.5 & 5.6 & 7 \\ & & & & & & & \\ \text { Graduados } & \mathbf{2 . 6} & \mathbf{3 . 4} & \mathbf{3 . 2} & \mathbf{4 . 5} & \mathbf{5 . 5} & \mathbf{5 . 9} & 11 \\ - & & & & & \end{array}$

Autoconfiança

\begin{tabular}{|cccccccc} 
Estudantes & 3.9 & 4.0 & 4.3 & 4.4 & 4.5 & 5.0 & 3 \\
Professores & 4.0 & 4.2 & 4.1 & 4.8 & 4.6 & 4.9 & 2 \\
Graduados & 3.5 & 4.3 & 4.4 & 4.5 & 5.0 & 5.1 & 6 \\
\hline
\end{tabular}

Teste Scheffé, $\mathrm{P} \varangle 0.05$ 
tivação profissional e a autoconfiança são, igualmente, os mais fracos de entre os seis agrupamentos. Em termos gerais, os professores inquiridos são mais benevolentes nas apreciações destes docentes, e os diplomados são os mais contundentes na avaliação negativa.

b) Aos elementos do grupo 2 foi imputada a designação de "Apenas corteses". As suas notações de cidadania são geralmente baixas, mas apresentam uma elevada pontuação em cortesia. AssemeIham-se a docentes simpáticos, mas que são pouco empenhados na preparação das aulas, pouco organizados e metódicos na leccionação, fracos promotores da participação dos alunos, e modestamente orientados para a ilustração da matéria com exemplos práticos e da vida pessoal. São alvo de cotações negativas de desempenho por parte de todos os tipos de inquiridos, especialmente os graduados. 0 s três tipos de inquiridos declaram que os efeitos por eles exercidos sobre a motivação profissional e a autoconfiança são igualmente fracos, embora melhores do que os ocorridos para o grupo anterior.

c) Os docentes englobados no terceiro agrupamento foram denominados "C onscienciosos": as suas pontuações nas duas primeiras dimensões de cidadania são fracas, mas expressam elevada orientação conscienciosa (e pautam-se por um espírito moderadamente cortês). São uma espécie de docentes que se preocupam com o rigor e organização das suas aulas, adoptam um relacionamento harmonioso e cortês, mas descuram a vertente prática das aulas e o fomento da participação dos alunos. D enotam uma cotação de desempenho globalmente positiva, embora modesta. $0 \mathrm{~s}$ professores que participaram nos estudos parece, no entanto, apreciarem relativamente bem este perfil nos seus antigos mestres. C om efeito, para além da razoavelmente el evada cotação de desempenho que lhes atribuem, declaram terem sido bastante influenciados por eles no que concerne à motivação profissional. É possível que tal se deva, fundamentalmente, ao pendor consciencioso.

d) No quarto grupo estão agrupados os elementos que nomeámos "Regulares". São medianamente orientados para todas as dimensões de cidadania. Em geral, todos os inquiridos os consideram razoavelmente bons docentes, embora seja de notar a menor apreciação de que são alvo por parte dos graduados. 0 s profes- 
sores que participaram do estudo, por seu turno, são mais benevolentes, denotando apreciar bastante este perfil nos seus antigos mestres. Em geral, todos os inquiridos consideram que eles influenciaram de modo positivo os seus níveis de motivação profissional e autoconfiança.

e) O s docentes do agrupamento "Profissionais diligentes" caracterizam-se por pontuações bastante el evadas em todas as dimensões de cidadania, recebendo cotações de desempenho igualmente expressivas por parte de estudantes, professores e graduados. A influência por eles exercida sobre as duas variáveis de impacto é globalmente bastante positiva, qualquer que seja o tipo considerado de inquiridos.

f) Finalmente, os docentes do sexto grupo receberam a designação de "Exemplares", devido ao facto de serem considerados excelentes cidadãos docentes em todas as dimensões comportamentais. 0 reflexo mais claro deste perfil está projectado na cotação de desempenho que todos os inquiridos Ihes atribuem - a mais elevada dentre todos os grupos. Os impactos exercidos sobre a motivação profissional e a autoconfiança são mais elevados do que os verificáveis em qualquer dos agrupamentos anteriores.

\section{Análise, discussão e conclusões}

0 primeiro elemento digno de menção a propósito dos dados expostos é o referente às boas propriedades psicométricas do instrumento de medida dos Cidoce. Com efeito, o modelo tetra-dimensional ajustase satiffatoriamente aos dados, as consistências internas de cada dimensão ultrapassam sistematicamente 0 mínimo de 0.70 sugerido por $\mathrm{N}$ unnally (1978), e a validade preditiva de cada categoria comportamental é assinalável. $\mathrm{H}$ á, por conseguinte, razões acrescidas para prosseguir as pesquisas com 0 recurso ao instrumento em causa.

Em segundo lugar, importa referir que os elementos empíricos evidenciados revelam que a excelência docente universitária implica que os professores promovam a participação dos alunos, confiram às aulas um pendor prático, sejam conscienciosos na preparação e organização das lições, e adoptem condutas cordiais e corteses. $N$ ão basta ser consciencioso, nem é suficiente ser simpático/cortês: é necessário conciliar as quatro categorias de cidadania. Estas concepções são perfilhadas pelos professores e diplomados, mas também pelos estudantes. 
Por conseguinte, contrariamente a uma ideia por vezes detectada na vida académica, afigura-se que os estudantes não procedem a apreciações naives acerca dos seus professores. Eles valorizam as quatro vertentes comportamentais e acolhem particularmente bem o professor que consegue combiná-las em alto grau. N ote-se, especialmente, o facto de cotarem de modo relativamente fraco os professores "A penas corteses". Consequentemente, a ideia frequentemente divulgada de que os estudantes fazem juízos enviesados acerca dos desempenhos docentes - deixando-se "iludir" com professores (apenas) simpáticos, amistosos e corteses! - só pode fazer carreira se se admitir... que esses enviesamentos são partilhados pelos professores e diplomados

O u seja: também aos "olhos" dos alunos, não basta ser cortês; também não basta ser consciencioso; nem é suficiente a conciliação das duas vertentes; o perfil mais valorizado é, efectivamente, o que se caracteriza por elevadas ori entações nas quatro categorias comportamentais G lobalmente, as suas concepções são muito semelhantes às dos actuais professores e dos já diplomados. Há, portanto, algumas razões para advogar que os estudantes demonstram uma perspectiva acerca da excelência da docência que contradiz algumas ideias pré-concebidas e relativamente comuns no meio académico.

Esta recorrente evidência empírica projecta sobre os resultados uma validade indubitável, conferindo grande dose de verossimilhança à noção de que os comportamentos pesquisados são susceptíveis de contribuir para os incrementos da qualidade no ensino superior. Ela é, aliás, convergente com os dados empíricos atinentes às "avaliações pelos estudantes da eficácia do professor" (v.g., Stringer \& Irving, 1998; Rowley, 1996) e às "avaliações pelos estudantes da qualidade educativa" (v.g., M arsh et al., 1998). A tendência geral exposta não deve, no entanto, obnubilar algumas particularidades decorrentes da cogitação entre as concepções de diplomados, estudantes e professores. Elas nã̃o diminuem a validade dos dados, antes Ihe conferem maior poder heurístico. Importa reter as mais relevantes:

Primeira: os diplomados (tal como os professores) ponderam as quatro categorias comportamentais docentes mais fortemente do que os estudantes. É presumível que a experiência profissional entretanto adquirida os torne mais aptos a avaliar a importância e os efeitos dos seus antigos mestres. A exposição à realidade do mundo do trabalho pode torná-los mais sensíveis à valia e (bom ou mau) exemplo dos seus antigos professores.

Segunda: para as mesmas configurações de cidadania docente (Tabela 4), os professores inquiridos tendem a ser mais benevolentes nas 
cotações de desempenho atribuídas aos seus antigos mestres e nos impactos que declaram ter deles recebido. Os diplomados, por seu turno, são tendencialmente mais contundentes nas apreciações negativas. No que respeita à benevolência dos professores, é possível que ela resulta da renitência sentida pelos próprios em atribuírem pontuações excessivamente negativas aos seus colegas de profissão. É igualmente presumível que, devido à experiência docente entretanto adquirida, sejam mais capazes de compreender as dificuldades da função e se sintam menos propensos a juízos extremadamente negativos. Relativamente aos diplomados, pode admitir-se que a sua maior contundência se deve à experiência profissional que Ihes suscita uma maior consciencialização das deficiências formativas recebidas de professores com fraco espírito de cidadania docente.

Terceira: mais do que os estudantes, os diplomados (e professores) atribuem à orientação prática uma importância relativa superior à imputada pelos estudantes. 0 mesmo pode ser dito a propósito da conscienciosidade. A argumentação anteriormente aduzida ajuda a explicar esta evidência. Com efeito, é possível que a experiência profissional os torne mais cientes da importância dos ensinamentos práticos que os professores Ihes transmitiram (ou não). E que lhes revele a importância da conscienciosidade profissional, isto é, do rigor, método e organização. Pode suceder que, com a experiência de vida, sintam que os antigos docentes mais conscienciosos foram aqueles que, no médio/longo prazo, vieram a produzir efeitos mais proveitosos nas suas vidas.

Q uarta: a cortesia é mais ponderada pelos diplomados do que pelos estudantes e professores. Ela representa, mesmo, a categoria comportamental que mais explica a respectiva autoconfiança. 0 dado pode parecer surpreendente, mas não deixa de chamar a atenção para a importância dos actos docentes não especificamente ligados aos conteúdos programáticos formais. 0 que os dados sugerem é que uma variável relacional como a cortesia docente é (continua a ser!) valorizada pelos indivíduos já ingressados no mundo do trabalho. Este dado apela para a consideração da evidência obtida por Rego (1999) quando verificou, num estudo longitudinal, que esta dimensão era a única com poder preditivo significativo do desempenho académico. Segundo o investigador, o resultado poderia significar uma de duas coisas:

a) É possível que os professores (des)corteses exerçam um efeito (des)motivador sobre os seus estudantes, induzindo-os a alterar os seus níveis de esforço e empenhamento, com repercussões no desempenho académico. 
b) M as também é verossímil que a relação detectada resulte da influência de uma terceira variável sobre os Cidoce e as classificações dos alunos, e não propriamente do efeito dos comportamentos dos docentes sobre 0 trabalho e desempenho dos estudantes. $\mathrm{N}$ a verdade, pode suceder que al guns professores tenham determinadas características de personalidade que os induzem a ser mais corteses e, simultaneamente, mais benevolentes na atribuição das notas.

O ra, o que os dados empíricos emergentes dos actuais estudos sugerem é que, porventura, a cortesia representa algo mais do que a génese da benevolência docente. Ela pode constituir, complementarmente com outros actos de cidadania, uma actividade docente de natureza sócio-afectiva com impactos significativos sobre a motivação, empenho, entusiasmo, satisfação, identificação pessoal, autoconfiança, identificação pessoal e maior disponibilidade para assumir responsabilidades dos estudantes (Podsakoff et al., 1990; H arvie \& Leiter, 1999; Yukl, 1998). Por essas vias, é susceptível de incrementar os níveis de dedicação ao trabalho, estimulação e aprendizagem (Stringer \& Irving, 1998).

Q uinta: as tendências detectadas são extensivas aos diplomados com vários tipos de curso e diferentes profissões. E parecem ser independentes do momento temporal em que o curso foi realizado. A consistência dos dados sugere, uma vez mais, a sua relevância e validade. Todavia, descortinou-se uma pequena tendência para que os diplomados em engenharias sejam mais sensíveis à orientação prática dos seus antigos docentes. 0 dado não é supreendente, se pensarmos no teor dos conteúdos formativos desses cursos. É presumível que a aprendizagem de matérias com forte conteúdo técnico e tecnológico seja mais fortemente promovida com exemplos práticos do que a aprendizagem de tópicos cujo conteúdo é mais científico, "cultural" ou humanístico.

Finalmente, importa reter um aspecto que, embora (aparentemente) colateral, pode ajudar a compreender as concepções manifestadas pelos inquiridos. $\mathrm{N}$ a verdade, tanto os estudantes como os professores e os diplomados direccionaram as suas escolhas para docentes que são por eles considerados "bons" ou "excelentes" (vide figura 1). A prevalência de escolhas de perfis docentes "positivos" é, por conseguinte, extensiva aos estudantes. Este dado parece contrariar uma noção corrente, segundo a qual os alunos são predominantemente "contestatários", especialmente atentos a casos "negativos", e pouco sensíveis às "excepções" positivas. E torna mais rica a evidência empírica obtida, pois sugere aquilo que eles 
valorizam especialmente bem - mais do que aquilo que não desejam. Sublinhe-se, todavia, que a tendência é mais expressiva para os professores e diplomados inquiridos do que para os estudantes. D aqui emergem dois comentários:

a) Por razões corporativistas, é possível que os docentes se sintam desconfortáveis na escolha e avaliação de "maus professores". Podem, designadamente, sentir que uma tal opção representa uma avaliação negativa indirecta da sua própria actividade.

b) Ao serem convidados a reflectir sobre os seus antigos mestres, é presumível que os professores e restantes diplomados recuperem da memória aqueles que mais se salientaram como modelos positivos para a sua própria actividade actual.

Figura 1

Distribuição das escolhas dos inquiridos pelas várias configurações decidadania docente

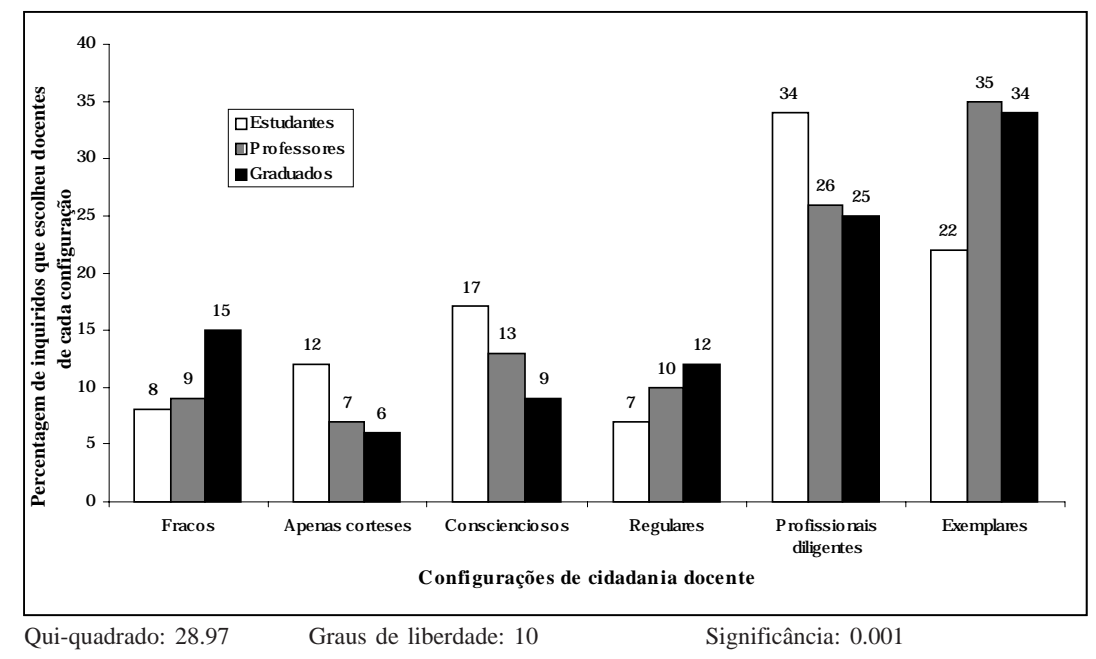

0 presente estudo contém algumas especificidades (mormente me todológicas), cujas insuficiências os estudos posteriores poderão suprir, mas cujas potencialidades poderão ser desenvolvidas:

a) $0 \mathrm{~s}$ dados relativos às variáveis dependentes e independentes foram recolhidos na mesma fonte. Por conseguinte, os riscos da 
variância do método comum (Podsakoff \& O rgan, 1986) são mais prováveis. $\mathrm{H}$ á, portanto, interesse em que pesquisas posteriores adoptem uma metodologia de "dupla fonte": al guns inquiridos descrevem o comportamento dos professores, e outros expressam os impactos e a cotação de desempenho. Para ultrapassar eventuais dificuldades de concretização de uma tal metodologia, pode revelar-se útil obter os dados a partir dos mesmos indivíduos em momentos distanciados no tempo.

b) U m dos factores de impacto (autoconfiança) carece de validação posterior, já que a sua interpretação suscita al gumas dificuldades.

c) A metodologia usada é correlacional, pelo que não é possível aduzir um nexo de causalidade entre as variáveis. Pode, por exemplo, suceder que os estudantes que obtiveram melhores classificações na disciplina (ministrada pelo professor que escoIheram para avaliação) procedam a racionalizações post hoc que os induzem a cotar positivamente o desempenho dos seus antigos professores, a declarar efeitos mais fortes na motivação e autoconfiança e a atribuir-Ihes cotações de cidadania mais elevadas. N esse caso, assistir-se-ia a uma relação de causalidade inversa à subjacente no presente estudo.

d) 0 facto de haver correlações fortes entre determinados comportamentos dos docentes e as cotações de desempenho que lhes são imputadas pelos seus alunos não implica, necessariamente, que esses comportamentos sejam determinantes para o desempenho académico. Importa, por conseguinte, prosseguir as pesquisas, na tentativa de se descortinar um padrão de relações que explique o poder explicativo dos Cidoce para 0 desempenho académico dos estudantes.

De qualquer modo, é de justiça realçar que os resultados aqui apresentados são consistentes com diversa evidência empírica, designadamente a que tem sido produzida no âmbito das "avaliações pelos estudantes da eficácia do professor" (v.g., Stringer \& Irving, 1998) e das "avaliações pelos estudantes da qualidade educacional" (v.g., M arsh et al., 1998; Rowley, 1996). Eles contribuem para a compreensão dos efeitos que os professores podem exercer sobre os estudantes e fornecem valor acrescentado num domínio que os estudos sobre 0 ensino superior vêm progressivamente enfatizando: a qualidade. Sugerem claramente que as quatro dimensões de cidadania estudadas são bastante valorizadas, 
tanto pelos docentes e diplomados que se debruçaram sobre os seus antigos docentes, como pelos estudantes que avaliaram os seus actuais professores. Todos consideram que as quatro categorias de cidadania definem vincadamente o perfil de um "bom" professor universitário e exercem efeitos sobre a sua motivação profissional e (menos expressivamente) autoconfiança.

É possível que isso ocorra porque os professores que agem como "bons cidadãos" funcionem como modelos passíveis de imitação, gerem ambientes promotores do envolvimento activo dos estudantes e do seu desenvolvimento, criem expectativas positivas nos seus alunos que induzem estes na tentativa de as cumprir, promovam as relações de confiança, transmitam entusiasmo, suscitem fenómenos de identificação pessoal, concitem satiffação e sentimentos de auto-eficácia, estimulem a aprendizagem, transmitam mensagens conducentes à assunção de responsabilidades.

N ão pode daqui extrair-se simplisticamente a tese de que os comportamentos simultaneamente valorizados por professores, estudantes e diplomados devem ser inseridos, de imediato, nos processos avaliativos da qualidade no ensino superior. $M$ as a convergência legitima a ideia de que os comportamentos aqui gizados constituem áreas de actuação de mais provável eficácia - seja para os docentes que pretendem adoptar posturas de "melhoria contínua", seja para as instituições que estão empenhadas em promover a adopção desses comportamentos pelos seus docentes.

Estes estudos representam, por conseguinte, um passo adicional na busca de factores de melhoria da área que diversos estudiosos vêm mencionando como crucial para a gestão da qualidade total: o processo ensinoaprendizagem. Eles ajudam, ainda, a desfazer um dos maiores equívocos detectáveis no discurso por vezes desenvolvido em torno da qualidade no ensino superior: a secundarização das perspectivas dos estudantes. $\mathrm{N}$ a génese de um tal caminho estão razões várias e não será possível elencar exaustivamente as mais prováveis e/ou verossímeis. M as uma se nos afigura mencionável: a tese segundo a qual os estudantes não estão capacitados para emitir juízos apropriados acerca da qualidade do ensino que lhes é ministrado. A presente investigação vai ao arrepio dessa ideia e sugere que ela só pode continuar a ser sustentada se admitirmos que... também os diplomados e os actuais professores carecem dessa capacidade!

Recebido para publicação em março de 2000. 


\section{THE UNIVERSITY TEACHER AS A GOOD CITIZEN: IN SEARCH OF QUALITY IN HIGHER EDUCATION}

ABST RACT: Thispaper extendspreviousresearch in the field of citizenship behaviors of university teachers (CBUT). It aims at showing how four dimensions of CBUT (participatory behavior, practical orientation, conscientiousness and courtesy) explain: a) the professional motivation and self-confidence of students; b) the way students evaluate teachers performance. Previous data obtained from students and teachers samples are retaken, and a sample of graduates is added. The whole sample comprises 249 students (who described the behaviors of an actual teacher of their choice) plus 123 teachers and 209 graduates (who were invited to report the behaviors of a former teacher). The main findings are the following: a) students, teachers and graduates consider that the four behaviors of their (actual or former) teachers influenced significantly their own professional motivation and self-confidence; b) the three types of participants in the study attribute a high value to the four CBUT when evaluating the performance of their (actual or former) teachers. The consistency of these findings suggests that the CBU T can be an important source of quality in higher education, namely asfor astheteaching-learning process isconcerned.

Key words: Q ualityin higher education; Citizenship behaviorsof university teachers, Self-confidence; Professional motivation.

\section{Referências bibliográficas}

BAILEY, D . \& BEN NETT, J.V. The realistic model of higher education. Quality Progress, nov. 1996, p.77-79.

BRYM AN , A. \& CRAM ER, D. Quantitative data analysis for social scientists. London: Routledge, 1990.

BYRNE, B.M. Structural Equation Modelling with Lisrel, Prelis, and Simplis. London: Lawrence Erlbaum Associates, 1998.

ELLIN GTON , H . \& ROSS, G. Evaluating teaching quality throughout a university. Q uality Assurance in Education, 2(2), 1994, p. 4-9.

FEIGEN BAU M, A.V. Q uality education and America's competitiveness. Q uality Progress, September, 1994, p. 83-84.

HACKMAN, J.R. \& WAGEMAN, R. Total quality management: Empirical, conceptual and practical issues. Administrative Science Q uarterly, 40, 1995, p. 309-342. 
HAN SEN, W.L. \& JACKSON, M. Total quality improvement in the classroom. Q uality in H igher Education, 2(3), 1996, p. 211-217.

HARVIE, P. \& LEITER, M .P. Engagement in learning: Teacher behavior and student response. Paper presented at the $107^{\text {th }}$ Annual Convention of the American Psychological Association, Boston, M assachusetts, 20-24 August, 1999.

HELM S, S. \& KEY, C.H. Are students more than costumers in the classroom? Quality Progress, September, 1994, p. 97-99.

H IN D LE, Tim. Como fazer comunicações. Livraria Civilização Editora, 1998.

HORINE, J.E., HAILEY, W.A. \& RUBACH, L. Shaping America's future. Quality Progress, 0 ctober, 1993, p. 41-60.

H ORSBURGH, M. Q uality monitoring in higher education: the impact on student learning. Q uality in Higher Education, 5(1), 1999 , p. 9-25.

JORESKOG, K. \& SORBOM, D. Lisrel 8: Structural Equation M odeling with the Simplis Command Language. Scientific Software International, 1993.

$\mathrm{KOH}$, W., STEERS, R., \& TERBORG, J. The effects of transformational leadership on teacher attitudes and student performance in Singapore. Journal of Organizational Behavior, 16, 1995, p. 319-333.

M ACKENZIE, S.B., PODSAKOFF, P.M . \& AHEARNE, M. Some Possible Antecedents and Consequences of In-Role and Extra-Role Salesperson Performance. Journal of M arketing, 62, Jul. 1998, p. 87-98.

M ARSH , H.W., HAU, K., CHUNG, C. et al. Confirmatory factor analyses of chinese students' evaluations of university teaching. Structural Equation Modeling, 5(2), 1998, p. 143-164.

MONTANO, C.B. \& UTTER, G.H. Total quality management in higher education. Q uality Progress, Aug. 1999, p. 52-59.

NETEM EYER, R.G., BO LES, J.S., M CKEE, D. et al. An Investigation Into the Antecedents of O rganizational Citizenship Behaviors in a Personal Selling Context. Journal of M arketing, 61, 1997, p. 85-98. 
N U N N ALLY, J.C. Psychometric Theory. $2^{\text {nd }}$ ed., N ew York: M cG rawH ill, 1978.

ORGAN, D. Organizational Citizenship Behavior: The Good Soldier Syndrome. Lexington, M A: Lexington Books, 1998.

. O rganizational Citizenship Behavior - its construct clean-up time. Human Performance, 10(2), 1997, p. 85-97.

ORGAN, D.W. \& PAINE, J.B. A new kind of performance for industrial and organizational psychology: Recent contributions to the study of organizational citizenship behavior. International Review of Indus trial and Organizational Psychology, 14, 1999, p. 338-368.

ORGAN , D.W. \& RYAN, K. A M eta-Analytic Review of Attitudinal and Dispositional Predictors of $O$ rganizational Citizenship Behavior. Personnel Psychology, 48, 1995, p. 775-802.

PESTAN A, M.H .\& GAGEIRO, J.N . Análise de dados em Ciências Sociais. Lisboa: Edições Sílabo, 1998.

PODSAKOFF, P.M., MACKENZIE, S.B., MOORMAN, R.H. et al. Transformational leader behaviors and their effects on followers' trust in leader, satisfaction, and organizational citizenship behaviors. Leadership Q uarterly, 1(2), 1990, p. 107-142.

RACE, P. Q uality for some? W hat about the rest? Q uality Assurance in Education, 2(2), 1994, p. 10-14.

REGO, A. Ilustração empírica da pertinência da longitudinalidade Cidadania docente versus desempenho dos estudantes universitários. Aceite para publicação nas Actas do Colóquio M etodologias de Investigação em Educação, Cidine, Instituto Politécnico de Castelo Branco, Portugal, 25-26 Jun. 1999.

REG O, A. \& SO USA, L. (1999a). Citizenship behaviors of university teachers and their impact on subordinates. Paper presented at the $57^{\text {th }}$ Annual Convention of International Council of Psychologists, Salem, M assachusetts, 15-19 Augusto, 1999a.

. Comportamentos de cidadania do professor: Sua importância para a comunidade escolar. Revista de Educação, VIII (1), 1999b, p. 57-63. 
I mpactos dos comportamentos de cidadania docente sobre os alunos universitários - A perspectiva dos estudantes e dos professores. Linhas Críticas 6(10), Universidade de Braślia, 2000, p. 9-30.

REIS, E. Análise de clusters: U m método de classificação sem preconceitos. Lisboa: ISCTE/G iesta, 1991.

ROWLEY, J. M easuring quality in higher education. Quality in Higher Education, 2(3), 1996, p. 237-255.

SCHARGEL, F.P. Teaching TQ M in a inner city high school. Quality Progress, Sept. 1994, p. 87-90.

SHEM WELL, D.J., YAVAS, U. \& BILGIN, Z. Customer-service provider relationships: An empirical test of a model of service quality, satisfaction and relationship-oriented outcomes. International Journal of Service Industry M anagement, 9(2), 1998, p. 155-168.

SIRVAN CI, M. Are students the true customers of higher education? Q uality Progress, O ctob. 1996, p. 99-102.

SKARLICKI, D.P. \& LATH AM , G.P. O rganizational citizenship behavior and performance in a university setting. Canadian Journal of Administrative Sciences, 12(3), 1995, p. 175-181.

SM ITH , C., ORGAN, D., \& NEAR, J. O rganizational Citizenship Behavior: Its $N$ ature and Antecedents, Journal of Applied Psychology, 68(4), 1983, p. 653-663.

ST RIN GER, M . \& IRW IN G, P. Students' evaluations of teaching effectiveness: A structural modelling approach. British Journal of Educational Psychology, 68, 1998, p. 409-426.

Van DYNE, L., CUMMINGS, L. L. \& PARKS, J. M. Extra-role behaviors: In pursuit of construct and definitional clarity (a Bridge over M uddied Waters). In: L.L. Cummings \& B.M. Staw (Eds.), Research in O rganizational Behavior, vol. 17, Greenwich, Connecticut: JAI Press, 1995, p. 215-285.

YORKE, M. This way QA? Quality Assurance in Education, 5(2), 1997, p. $97-100$.

YUKL. G. Leadership in organizations. $4^{\text {th }}$ ed. Englewood Cliffs, $N$ ew Jersey: Prentice H all, 1998. 
ZABALZA, M. Coordenadas básicas para una docencia de calidad en la U niversidad: Q ué caracteriza la calidad de los docentes y la docencia universitaria. Conferência apresentada ao I Simposium Iberoamericano sobre Didáctica U niversitária, Santiago de Compostela, 2-4 de dez. 1999.

ZBARACKI, M.J. The rhetoric and reality of total quality management. Administrative Science Quarterly, 43, 1998, p. 602-636. 
Anexo

Caracterização da amostra dediplomados

\begin{tabular}{|c|c|}
\hline Actividade profissional & $\begin{array}{c}\text { Quantidade de } \\
\text { inquiridos }\end{array}$ \\
\hline Professores do ensino básico & 7 \\
\hline Professores do ensino secundário & 71 \\
\hline Professores do ensino superior & 14 \\
\hline Formadores & 3 \\
\hline Técnicos superiores em várias organizações públicas e privadas & 68 \\
\hline \multirow[t]{2}{*}{ Directores, gestores, administradores, gerentes } & 46 \\
\hline & $\begin{array}{c}\text { Quantidade de } \\
\text { inquiridos } \\
\end{array}$ \\
\hline Cursos via-ensino e "humanidades" & 52 \\
\hline Ciências (Química, Física, Biologia, Geologia) & 32 \\
\hline Engenharias & 69 \\
\hline Gestão e Economia & 45 \\
\hline \multirow[b]{2}{*}{ Há quanto tempo terminaram o curso? } & 11 \\
\hline & $\begin{array}{c}\text { Quantidade de } \\
\text { inquiridos } \\
\end{array}$ \\
\hline Menos de 3 anos & 88 \\
\hline Entre 3 e 8 anos & 63 \\
\hline Mais de 8 anos & 58 \\
\hline
\end{tabular}

